\title{
Analysis of Well Being of People Practicing Yoga
}

\author{
K. Madhava Chandran ${ }^{1} *$
}

\section{ABSTRACT}

Background: De-stressing for achieving a sense of well being has become an absolute necessity for people to reduce psycho-somatic disorders. The degree to which one experiences control over one's response to life events will have a buffering effect for adverse life events and will enhance wellbeing. Subjective wellbeing indicates how people evaluate their lives in terms of feelings of wellbeing or the lack of it. Yoga helps in significant reduction of stress, contributing to a feeling of better wellbeing. Aim: This study analyses the effect of yoga on subjective well being of people. Research Design: Survey method was adopted for the study. Sample: Consisted of 100 randomly selected yoga practitioners. Tools used: They were interviewed using a questionnaire consisting of 13 subjective well being parameters (OECD, 2013), with three responses, scored as 3, 2 and 1. Subjective Well Being Index (SWBI) was worked out as the sum of the scores of the parameters. The data was analyzed through analysis of variance. Results: The mean SWBI of yoga practitioners mostly improves with the years of yoga practice. However, even up to two years of yoga practice contributes to a very promising condition of well being, with more than $89 \%$ of the respondents experiencing either very much or slight improvement / reduction in all the well being parameters. More than 10 years of yoga practice gives the maximum SWBI of 37, equivalent to about $95 \%$ of the maximum possible index, while 6 to 10 years of yoga contributes to an index of about 34. Even though the SWBI of up to 2 years, 2 to 4 years and 4 to 6 years of yoga practice are statistically on par, they differ significantly from that of the yoga practice categories above 6 years. 6 to 8 years and 8 to 10 years of yoga contribute to SWBI, which is also significantly different from the SWBI of more than 10 years practitioners. Conclusion: The results of the study establish the effect of yoga in achieving a feeling of well being among people, which would ultimately contribute to better physical health also for them. Hence, psycho-somatic disorders existing under the fast, hectic and tense conditions in the society can be reduced considerably through the practice of relaxation techniques such as yoga. In this context, it will be worthwhile if institutions such as yoga centres, recreational clubs, residents' associations, schools, offices etc. take initiative in popularizing such mind - body relaxation

\footnotetext{
${ }^{1} \mathrm{Ph} . \mathrm{D}$, Trust Member of the Patanjali Yoga Research Centre, Kozhikode, Kerala, India

*Responding Author

Received: February 1, 2017; Revision Received: February 21, 2017; Accepted: February 28, 2017

(C) 2017 Chandran M; licensee IJIP. This is an Open Access Research distributed under the terms of the Creative Commons Attribution License (www.creativecommons.org/licenses/by/2.0), which permits unrestricted use, distribution, and reproduction in any Medium, provided the original work is properly cited.
} 


\section{Analysis of Well Being of People Practicing Yoga}

techniques through awareness programs which also include information from research carried out, demonstration of the techniques etc. with the objective of creating a healthy society.

Keywords: Stress, Subjective well being, Yoga

People find it difficult to adjust under the fast, hectic and stressful conditions of life, resulting in health problems and consequent medical treatment with harmful drugs. De-stressing for achieving a sense of well being is the need of the hour in the society in order to reduce psychosomatic disorders. Personal wellbeing has been conceptualized as optimal functioning rather than merely absence of pathology. Research into wellbeing has centered on the term subjective wellbeing, measured by overall satisfaction with life and by satisfaction across various life domains. The degree to which one experiences control over one's response to life events (perceived control) is considered to have a buffering effect for adverse life events and will enhance wellbeing. Subjective wellbeing indicates how people evaluate their lives in terms of feelings of wellbeing or the lack of it.

Yoga is considered to be one of the effective tools available to overcome various physical and mental problems. Yoga aims at an integrated and harmonious development of all the potentialities of man, with significant reduction in stress, and consequently, better feeling of wellbeing. Yoga is reported to have a positive effect on mood, stress, anxiety, depression, mindfulness and other quality of life measures (Michalsen et al., 2005; Granath et al, 2006; Oken et al., 2006). The influence of yoga and meditation on subjective wellbeing of people have been reported (Gopukumar and Hussain Ali, 2002; Kamakhy Kumar, 2004). The effect of yoga on subjective wellbeing would result from its impact on health, purpose in life and perceived control. Setterlind (1983) reported the effect of meditation in bringing a positive change in the well-being of subjects. Malathi et al. (2000) observed a significant improvement in majority of the subjective well-being factors in healthy volunteers after four months of yoga practice.

\section{Objective}

1. This study was carried out in order to analyze the effect of yoga on subjective well being of people.

\section{METHODOLOGY}

A random sample of 100 people, who practice yoga learned from Patanjali Yoga Research Centre, Kozhikode District, Kerala State, India, was selected for the study. The sample consisted of people practicing yoga for a period of up to ten years and above. They were interviewed using a questionnaire consisting of 13 subjective well being parameters (OECD, 2013). The responses to improvement / reduction in the parameters through the practice of yoga, namely, very much, slight, no improvement / reduction were scored as 3, 2 and 1 respectively. The total score of the parameters was worked out as the subjective well being index of the respondent. The data was 


\section{Analysis of Well Being of People Practicing Yoga}

analyzed through analysis of variance (ANOVA). The data has been presented in the paper as percentages and scores / index.

\section{RESULTS}

The data on subjective well being parameters and index has been presented under different periods of yoga practice, starting from up to two years to more than 10 years. The Analysis of Variance (ANOVA) for the mean scores of various parameters under different periods of yoga practice is shown in Table 1 . Table 2 shows the ANOVA for the mean subjective well being index of various yoga practice categories.

Table 1. ANOVA of subjective well being parameter scores

\begin{tabular}{|c|c|c|c|c|c|c|c|}
\hline $\begin{array}{l}\text { Duration } \\
\text { of yoga } \\
\text { practice } \\
\text { (years) }\end{array}$ & $\begin{array}{l}\text { Mean } \\
\text { score for } \\
\text { happiness }\end{array}$ & $\begin{array}{l}\text { Mean } \\
\text { score for } \\
\text { calmness }\end{array}$ & $\begin{array}{l}\text { Mean } \\
\text { score for } \\
\text { relaxation }\end{array}$ & $\begin{array}{l}\text { Mean } \\
\text { score for } \\
\text { life } \\
\text { enjoyment }\end{array}$ & $\begin{array}{l}\text { Mean } \\
\text { score for } \\
\text { tiredness }\end{array}$ & $\begin{array}{l}\text { Mean } \\
\text { score for } \\
\text { tension }\end{array}$ & $\begin{array}{l}\text { Mean } \\
\text { score for } \\
\text { loneliness }\end{array}$ \\
\hline Up to 2 & 2.50 & 2.38 & 2.44 & 2.31 & 2.38 & 2.50 & 2.68 \\
\hline $2-4$ & 2.75 & 2.25 & 2.58 & 2.50 & 2.33 & 2.42 & 2.25 \\
\hline $4-6$ & 2.89 & 2.56 & 2.89 & 2.22 & 2.22 & 2.00 & 3.00 \\
\hline $6-8$ & 2.33 & 3.00 & 2.33 & 3.00 & 3.00 & 3.00 & 2.67 \\
\hline $8-10$ & 2.60 & 2.80 & 2.40 & 3.00 & 3.00 & 2.80 & 2.60 \\
\hline$>10$ & 3.00 & 2.60 & 3.00 & 2.80 & 3.00 & 2.60 & 3.00 \\
\hline & $\begin{array}{l}\mathrm{F}=1.498 \\
\text { Sig. } \\
p<0.20\end{array}$ & $\begin{array}{l}\mathrm{F}= \\
1.625 \\
\text { Sig. } \\
p<0.20\end{array}$ & $\begin{array}{l}F=1.545 \\
\text { Sig. } \\
p<0.20\end{array}$ & $\begin{array}{l}F=3.02 \\
\text { Sig. } \\
p<0.01\end{array}$ & $\begin{array}{l}\mathrm{F}=3.995 \\
\text { Sig. } \\
p<0.01\end{array}$ & $\begin{array}{l}\mathrm{F}= \\
2.824 \\
\text { Sig. } \\
p<0.05\end{array}$ & $\begin{array}{l}\mathrm{F}=2.073 \\
\text { Sig. } \\
p<0.10\end{array}$ \\
\hline
\end{tabular}

Table 2. ANOVA of subjective well being index of the yoga practitioners

\begin{tabular}{|l|l|}
\hline Duration of yoga practice (years) & Mean subjective well being index (SWBI) \\
\hline Up to 2 & 31.35 \\
\hline $2-4$ & 32.17 \\
\hline $4-6$ & 32.11 \\
\hline $6-8$ & 34.33 \\
\hline $8-10$ & 34.20 \\
\hline$>10$ & 37.00 \\
\hline \multicolumn{2}{|c|}{} \\
Sig. $p<0.05 \quad$ CD $=1.68$ \\
\hline
\end{tabular}

Table 3 gives the proportion of yoga practitioners reporting very much improvement / reduction in subjective well being parameters. Reduction applies to tiredness, tension, worry, anger and loneliness only. ANOVA of the percentage of respondents reporting very much improvement / reduction in various parameters under two categories of yoga practice, namely, up to 2 years and more than 2 years is shown in Table 4.

(c) The International Journal of Indian Psychology, ISSN 2348-5396 (e) | ISSN: 2349-3429 (p) | 162 
Table 3. Respondents reporting very much improvement / reduction in subjective well being parameters through yoga practice

\begin{tabular}{|c|c|c|c|}
\hline \multirow[t]{2}{*}{ Sl. No. } & \multirow[t]{2}{*}{$\begin{array}{l}\text { Subjective well being } \\
\text { parameter }\end{array}$} & \multicolumn{2}{|c|}{$\begin{array}{l}\text { Respondents (\%) reporting very much } \\
\text { improvement / reduction* in the parameter with }\end{array}$} \\
\hline & & $\begin{array}{l}\text { Up to } 2 \text { years yoga } \\
\text { practice }\end{array}$ & $\begin{array}{l}>\quad 2 \text { years yoga } \\
\text { practice }\end{array}$ \\
\hline 1 & Happiness & 64.2 & 77.3 \\
\hline 2 & Contentment & 71.4 & 90.9 \\
\hline 3 & Calmness & 33.3 & 68.2 \\
\hline 4 & Relaxation & 57.1 & 72.7 \\
\hline 5 & Enjoyment in life & 42.9 & 63.6 \\
\hline 6 & Enthusiasm & 60.7 & 68.2 \\
\hline 7 & Concentration & 39.3 & 50.0 \\
\hline 8 & Memory & 42.9 & 50.0 \\
\hline 9 & Tiredness & 35.7 & 72.7 \\
\hline 10 & Tension & 46.4 & 50.0 \\
\hline 11 & Worry & 32.1 & 45.5 \\
\hline 12 & Anger & 39.3 & 31.8 \\
\hline 13 & Loneliness & 64.2 & 86.4 \\
\hline
\end{tabular}

*Reduction applies to the parameters, namely, Tiredness, Tension, Worry, Anger and Loneliness

Table 4. ANOVA of respondents reporting very much improvement / reduction in subjective well being parameters through yoga practice

\begin{tabular}{|l|l|l|}
\hline $\begin{array}{l}\text { Years of } \\
\text { practice }\end{array}$ & $\begin{array}{l}\text { Respondents (\%*) reporting very much } \\
\text { improvement / reduction in subjective well being } \\
\text { parameters }\end{array}$ & F \\
\hline Up to 2 & 47.7 & 9.23 \\
\hline$>2$ & 65.9 & Sig. $p<0.01$ \\
\hline
\end{tabular}

*Mean percentage considering all the subjective well being parameters

Table 5 and 6 respectively show the proportion of yoga practitioners experiencing slight improvement / reduction in subjective well being parameters, and ANOVA of the percentage of respondents reporting slight improvement / reduction in various parameters under two categories of yoga practice, namely, up to 2 years and more than 2 years

(C) The International Journal of Indian Psychology, ISSN 2348-5396 (e) | ISSN: 2349-3429 (p) | 163 
Table 5. Respondents reporting slight improvement / reduction in subjective well being parameters through yoga practice

\begin{tabular}{|c|c|c|c|}
\hline \multirow[t]{2}{*}{ Sl. No. } & \multirow[t]{2}{*}{$\begin{array}{l}\begin{array}{l}\text { Subjective well being } \\
\text { parameter }\end{array} \\
\end{array}$} & \multicolumn{2}{|c|}{$\begin{array}{l}\text { Respondents (\%) reporting slight improvement } \\
\text { reduction* in the parameter with }\end{array}$} \\
\hline & & $\begin{array}{l}\text { Up to } 2 \text { years yoga } \\
\text { practice }\end{array}$ & $\begin{array}{l}>2 \text { years yoga } \\
\text { practice }\end{array}$ \\
\hline 1 & Happiness & 32.1 & 22.7 \\
\hline 2 & Contentment & 25.0 & 09.1 \\
\hline 3 & Calmness & 63.0 & 31.8 \\
\hline 4 & Relaxation & 35.7 & 27.3 \\
\hline 5 & Enjoyment in life & 53.6 & 36.4 \\
\hline 6 & Enthusiasm & 28.6 & 31.8 \\
\hline 7 & Concentration & 53.6 & 50.0 \\
\hline 8 & Memory & 53.6 & 50.0 \\
\hline 9 & Tiredness & 64.3 & 22.7 \\
\hline 10 & Tension & 53.6 & 45.5 \\
\hline 11 & Worry & 64.3 & 40.9 \\
\hline 12 & Anger & 53.6 & 59.1 \\
\hline 13 & Loneliness & 27.3 & 13.6 \\
\hline
\end{tabular}

*Reduction applies to the parameters, namely, Tiredness, Tension, Worry, Anger and Loneliness

Table 6. ANOVA of respondents reporting slight improvement / reduction in subjective well being parameters through yoga practice

\begin{tabular}{|l|l|l|}
\hline $\begin{array}{l}\text { Years of yoga } \\
\text { practice }\end{array}$ & $\begin{array}{l}\text { Respondents (\%*) reporting slight improvement / } \\
\text { reduction in subjective well being parameters }\end{array}$ & F \\
\hline Up to 2 & 46.8 & 4.87 \\
\hline$>2$ & 33.9 & Sig. $p<0.05$ \\
\hline
\end{tabular}

*Mean percentage considering all the subjective well being parameters

\section{DISCUSSION}

When comparing the subjective well being of people based on period of yoga practice through analysis of variance, the $\mathrm{F}$ value is found to be significant for the difference in mean score of the parameters, namely, happiness, calmness, relaxation, enjoyment in life, tiredness, tension and loneliness (Table 1). It can also be seen that, for happiness, relaxation, tiredness and loneliness, the maximum score of 3 (indicating very much improvement / reduction in the parameter) is observed for all the respondents having more than 10 years of yoga practice. Life enjoyment also shows a very high score of 2.80 for this group.

It can be made out from Table 2 that the mean subjective well being index of yoga practitioners is mostly improving with the years of yoga practice. More than ten years of yoga practice gives an index of 37, equivalent to about 95\% of the maximum possible index of 39, while 6 to 10 years of yoga contributes to an index of about 34 , which is equivalent to about $88 \%$ of the

(c) The International Journal of Indian Psychology, ISSN 2348-5396 (e) | ISSN: 2349-3429 (p) | 164 


\section{Analysis of Well Being of People Practicing Yoga}

maximum possible index. The analysis of variance is significant at $p<0.05$ (Table 2). Considering the CD value of 1.68 (Table 2), it can be inferred that up to 2 years of yoga practice gives a subjective well being Index (SWBI), which is significantly different from that of the respondents having 6 to 8 years, 8 to 10 years and more than 10 years of yoga practice. Similarly, 2 to 4 years contributes to a SWBI, which is significantly different from the SWBI of 6 to 8 years, 8 to 10 years and more than 10 years categories. 4 to 6 years shows a SWBI, which is significantly different from 6-8 years, 8 to 10 years and more than 10 years. 6 to 8 years and 8 to 10 years of yoga practice contribute to a SWBI, which is significantly different from the SWBI of people practicing yoga for more than 10 years (Table 2).

It may be inferred from the CD value shown in Table 2 that there is no statistically significant difference in SWBI of people falling within various yoga practice categories up to 6 years. Similarly, the SWBI of 6 to 8 years and 8 to 10 years also do not differ significantly.

It may be noted that even up to 2 years of yoga practice is contributing to a very promising condition of well being for people, since the SWBI of this category of yoga practitioners is 31.35 (Table 2), which is equivalent to about $80 \%$ of the maximum possible subjective well being index. The maximum index will be obtained only when the yoga practitioner is able to achieve very much improvement / reduction for all the well being parameters. Similarly, even though there exists statistically significant difference in the proportion of people experiencing very much improvement / reduction in subjective well being parameters between up to 2 years and more than 2 years yoga practice categories (Table 4), it can be made out from the data presented in Tables 3 and 5 that, more than $89 \%$ of people, who have practiced yoga for a period of up to 2 years, experience either very much or slight improvement / reduction in all the well being parameters. This is a positive trend, indicating that lesser period of yoga practice can also help the practitioner in attaining a good sense of well being. This information could help in correcting the outlook of some people, who feel that a very long period of yoga practice is required to attain benefits (personal observation of the author)

The analysis of variance of the percentage of respondents reporting slight improvement / reduction in the subjective well being parameters under up to 2 years and more than 2 years yoga categories also shows a significant $\mathrm{F}$ value, even though comparatively more people report so under the first than the second category (Table 6). This is because more number of people with more than 2 years yoga experience (second category) have reported very much improvement / reduction in the subjective well being parameters, when compared to up to 2 years (Table 4)

\section{CONCLUSIONS}

The results of this study confirm the effect of yoga in achieving a feeling of well being among people, which is in line with similar studies carried out by other researchers. This will also contribute to better physical health, considering the fact that the lack of wellness and peace at the 


\section{Analysis of Well Being of People Practicing Yoga}

mental level is an important factor influencing the incidence of many diseases. Hence, the occurrence of many psycho-somatic disorders in our society can be reduced considerably through the practice of relaxation techniques such as yoga. This assumes relevance in the present day context, where people mostly lead a fast, hectic and tense life as an outcome of the unavoidable necessities of family / social commitments, work pressure etc. In this context, it will also be worthwhile if institutions such as yoga centres, recreational clubs, residents' associations, schools, offices etc. take initiative in popularizing such mind - body relaxation techniques through awareness and demonstration programs. which should also include information generated from research carried out, with the objective of creating a healthy society.

\section{Acknowledgement}

I would like to express my sincere gratitude to Sri. Unniraman, P., Yogacharya and Director of Patanjali Yoga Research Centre, Kozhikode, Kerala, India for giving me the opportunity to conduct this study. I also appreciate his noble endeavour to promote the yoga centre as a research institution by carrying out studies on yoga, meditation etc.

Conflict of Interests: The author declared no conflict of interests.

\section{REFERENCES}

Gopukumar, K., and Hussain Ali, M. (2002). "Meditation - A harbinger of subjective wellbeing”, Journal of Personality and Clinical Studies, 19: 93 to102

Granath, J., Ingvarsson, S., von Thiele, U., and Lundberg, U. (2006). "Stress management: A randomised study of cognitive behavioural therapy and yoga”, Cognitive Behaviour Therapy, 35(1): 3 to 10

Kamakhya, K. (2004). "Yoga nidra and its impact on students well-being”, Yoga Mimamsa, 36: 71 to 76

Malathi, A., Damodaran, A., Shah, N., Patil, N. and Maratha, S. (2000). "Effect of yogic practices on subjective well-being”, Indian Journal of Physiology and Pharmacology, 44: 202 to 206

Michalsen, A., Grossman, P., Acil, A., Langhorst, J. and Ludtke, R., Esch, T., et al. (2005). "Rapid stress reduction and anxiolysis among distressed women as a consequence of a three-month intensive yoga program”, Medical Science Monitor, 11(12): 555 to 561

OECD (2013). OECD Guidelines for Measuring Subjective Wellbeing. OECD Publishing, Accessed from http://dx.doi.org/10.1787/9789264191655- en (December 21, 2015)

Oken, B.S., Zajdel, D., Kishiyama, S., Flegal, K., Dehen, C., Haas, M., et al. (2006). "Randomized, controlled, six-month trial of yoga in healthy seniors: Effects on cognition and quality of life”, Alternative Therapies, 12(1): 40 to 47

Setterlind, S. (1983). "Relaxation training in School: Review of research and empirical studies", Goteborg, Sweden: Acta Universities Gothoburgensis

How to cite this article: Chandran M (2017), Analysis of Well Being of People Practicing Yoga, International Journal of Indian Psychology, Volume 4, Issue 2, No. 92, ISSN:2348-5396 (e), ISSN:2349-3429 (p), DIP:18.01.118/20170402, ISBN:978-1-365-78192-6 